\title{
Semantics of the classifiers in some Indian languages
}

\author{
Ritesh Kumar \\ Bornini Lahiri \\ Atanu Saha \\ Sudhanshu Shekhar \\ riteshkrjnu@gmail.com \\ lahiri.bornini@gmail.com \\ atanu.jnu@gmail.com \\ shekhar921@gmail.com
}

Centre for Linguistics, Jawaharlal Nehru University. New Delhi

\begin{abstract}
In the present paper, we present a detailed description of the classifier systems of five Indian languages-- Mizo, Galo, Tagin (all belongs to the Tibeto-Burman family), Assamese (Indo-Aryan) and Malto (Dravidian). It is observed that the classifiers are a predominant feature in the Tibeto-Burman and we observe an extensive classifier system in these languages. There is no equivalent classifier system in other language families. However in the languages belonging to Eastern India, irrespective of the family, there is some sort of classifier system. Thus classifiers seem to be an areal feature in most of the Eastern and whole of the North-Eastern India. The purpose of the paper is to study if there is some semantic similarity among the classifier systems across language families in this area and thus to see if it is indeed an areal feature. It is just a preliminary description of an ongoing research in which we intend to study many more languages and include languages from the Austro-Asiatic family (such as Khasi and Munda languages spoken in Jharkhand) as well.
\end{abstract}

\section{Introducing Classifiers}

There are two kinds of noun classification systems found in the languages of the world - noun class system and classifier system. Classifier languages can again be categorised into six typesnoun classifiers, numeral classifiers, classifiers in possessive constructions, verbal classifiers, locative classifiers and deictic classifiers. All these systems classify nouns on the semantic basis. But they differ morphosyntactically as well as on the basis of the preferred semantic features. Noun class systems are those in which the classification of Noun is generally done on the basis of such semantic categories as animacy, sex, humanness and sometimes shape. The noun class systems are marked by a finite and limited number of classes in which nouns can be classified. Thus in a language like Hindi, Nouns are classified into two classes. However, it can go up to 10 as in some Bantu languages and even to several dozen as in some South American languages.

The classifier languages differ from the class languages on the account of always being morphologically represented. It is not necessary for every noun, numeral or verb to occur with a classifier. And one noun may take more than one classifier depending on what property of the noun is being emphasized. In Noun classifier languages, the classifier comes with the Noun while in Numeral classifier languages, it is represented on a numeral or a quantifier (and so it comes only in the cases where noun comes with the numeral or the quantifier). Noun classifiers are generally independent words which typically mark distinctions on the basis of humans, flora, fauna, natural objects, artefacts, food (flesh/vegetable), edibility, portability, kinship, and other culturally important concepts. Numeral classifiers categorize the nouns in terms of its animacy, physical or functional properties, and cultural elements.

\section{Galo: A Tibeto-Burman Language}


Galo is a Tibeto-Burman language spoken mainly in the southern half of the West Siang district of Arunachal Pradesh and some parts of East Siang and Upper Subansiri also. It is a numeral classifier system i.e., classifiers occur only when a numeral comes with the noun. The classifiers and numerals attach to the noun in the following order - N[NUM-CL+NUM]. Galo classifies the objects according to their shape, size and dimensions. Some of the numeral classifiers used in the language are as follows.

\begin{tabular}{|c|c|c|}
\hline Classifiers & Type of Noun & Example \\
\hline ho & long slender object & $\begin{array}{l}\text { adrom ho-ken } \\
\text { hair CL-One } \\
\text { a strand of hair }\end{array}$ \\
\hline pa & not very long, but fleshy and is covered & $\begin{array}{l}\text { yoi pa-ken } \\
\text { fish CL-One } \\
\text { one fish }\end{array}$ \\
\hline bor & thin piece of cloth, a leaf or a piece of paper & $\begin{array}{l}\text { eji bor-ken } \\
\text { clothCL-One } \\
\text { a piece of cloth }\end{array}$ \\
\hline tak & objects which has hard surface & $\begin{array}{ll}\text { konke } & \text { tak- } \\
\text { ken } & \\
\text { stool } & \text { CL-One } \\
\text { One stool } & \\
\end{array}$ \\
\hline pu & round or circular objects & $\begin{array}{l}\text { pupə pu-ken } \\
\text { egg CL-One } \\
\text { an egg }\end{array}$ \\
\hline pom & bunch of ants, keys or flowers & $\begin{array}{ll}\text { tarok } & \text { pom-ni } \\
\text { Ants } & \text { CL- two } \\
\text { Two ants } & \\
\end{array}$ \\
\hline gob & measurement with fingers & $\begin{array}{ll}\text { lakco } & \text { gob- } \\
\text { ken } & \text { CL- } \\
\text { Finger } & \\
\text { One } & \\
\quad \text { one finger } & \end{array}$ \\
\hline $\operatorname{cin}$ & a pinch of something & $\begin{array}{l}\text { alo cin-ken } \\
\text { Salt CL-One } \\
\text { a pinch of salt }\end{array}$ \\
\hline
\end{tabular}

Besides these numeral classifiers, Galo exhibit a very interesting phenomenon of partially reduplicated numeral classifiers. In cases where nouns do not take any classifier as such, the last syllable of the noun is reduplicated and attached to the numeral. This partially reduplicated syllable functions as the numeral classifier for that noun. Some of the examples are as follows

\begin{tabular}{|l|l|l|}
\hline Classifiers & Noun & Example \\
\hline lak & Used for hands only & $\begin{array}{l}\text { alak lak-ken } \\
\text { Hand CL- One } \\
\text { One hand }\end{array}$ \\
\hline $\mathbf{m a}$ & & $\begin{array}{l}\text { joma ma-om } \\
\text { Dream } \quad \text { CL-Three }\end{array}$ \\
\hline
\end{tabular}




\begin{tabular}{|l|l|l|}
\hline & & Three dreams \\
\hline lo & for day & $\begin{array}{l}\text { alo lo-ken } \\
\text { day CL-One } \\
\text { One day }\end{array}$ \\
\hline
\end{tabular}

\section{Tagin: A close kin of Galo}

Tagin is mainly spoken in the Upper Subansiri district of Arunachal Pradesh. It is also a numeral classifier language. It has a very elaborate system of Numeral Classifiers with a small class of basic classifiers, based on shape, size and function. No reference to humanness or animacy is related. Tagin classifiers follow the same pattern as Galo i.e.,N [NUM-CL+NUM]

Like Galo there are some basic classifiers which are based on shape, size and function and there are some classifiers which come for single entity. Some examples of classifiers which map entities based on shape, size and function are as follows.

\begin{tabular}{|c|c|c|}
\hline Classifiers & Type of Noun & Example \\
\hline ta & two dimensional objects & $\begin{array}{l}\text { sintak ta-nu } \\
\text { board CL-5 } \\
\text { Five boards }\end{array}$ \\
\hline Сә & round small objects & $\begin{array}{l}\text { tərop cə-nu } \\
\text { ant CL-5 } \\
\text { Five ants }\end{array}$ \\
\hline so & long, cylindrical objects & $\begin{array}{l}\text { gəri so-pi } \\
\text { vehicle CL-4 } \\
\text { Four vehicles }\end{array}$ \\
\hline da & narrow objects & $\begin{array}{ll}\text { əsəy } & \text { da-ni } \\
\text { firewood } & \text { CL-two }\end{array}$ \\
\hline bor & broad objects & $\begin{array}{l}\text { one bor-ni } \\
\text { leaf CL-2 } \\
\text { Two leaves }\end{array}$ \\
\hline $\mathbf{n \varepsilon}$ & reproductive entities & $\begin{array}{l}\text { nime ne- pi } \\
\text { woman CL- four } \\
\text { Four Women }\end{array}$ \\
\hline pu & round objects & $\begin{array}{l}\text { pupu } \quad \text { pul--kin } \\
\text { egg CL--one } \\
\text { One Egg }\end{array}$ \\
\hline di & certain kind of elevation. & $\begin{array}{l}\text { modi di-kin } \\
\text { Mountain CL -one } \\
\text { One mountain }\end{array}$ \\
\hline
\end{tabular}

Moreover Tagin also exhibits the phenomenon of partially (as well as fully) reduplicated classifiers. These classifier morphemes are derived from reduplicating the last syllable of the referent nouns. Here are a few examples:-

\begin{tabular}{|l|l|l|}
\hline Classifiers & Noun & Example \\
\hline harpen & half pants & harpen pen-rin \\
\hline
\end{tabular}




\begin{tabular}{|c|l|l|}
\hline & & $\begin{array}{l}\text { half pant CL - ten } \\
\text { ten half pants }\end{array}$ \\
\hline ma & dead bodies & $\begin{array}{l}\text { soma ma-om } \\
\text { dead body CL -three } \\
\text { three dead bodies }\end{array}$ \\
\hline kuk & bag & $\begin{array}{l}\text { rakuk kuk- pi } \\
\text { bag CL -seven } \\
\text { seven bags }\end{array}$ \\
\hline ta & shoes & $\begin{array}{l}\text { juta ta- rin } \\
\text { shoe CL-ten } \\
\text { ten shoes }\end{array}$ \\
\hline
\end{tabular}

\section{Mizo: Another Tibeto-Burman Language}

Mizo is again a Tibeto-Burman language spoken throughout the state of Mizoram, parts of southern Manipur and the eastern Zampui hills of Tripura.

Mizo is also a classifier language and it has both Noun classifiers and Numeral classifiers. Only animates in the language takes up Noun classifiers, inanimate are not classified. The distinctions for Noun classifiers are mainly made by Gender Markers in [+Human] while the classifiers for [Human] are Gender Markers and Change of State like pre and post- reproduction as well as prenailed/horned or post-nailed/horned. The distinction for Numeral classifiers is made from the shapes and size of the objects. For Noun classifiers, Mizo follows N-CL word order while for numeral classifiers, it follows the usual Tibeto-Burman order of N[NUM CL+NUM].

There has been an interesting observation in Mizo where the numeral classifiers for mass nouns [+cumulative] take a state of action.

\section{Mizo Noun classifier system}

The system of categorization of nouns in Mizo reveals the fact that the language is a noun classifier language. The evidences for this proposal are as follows:

It is a fact that in a noun classifier language every noun does not necessarily take a noun classifier and a noun can occur with more than one classifier.

In Mizo [pa] is a classifier used to denote masculinity and it comes with human nouns especially. But it may also occur with professional nouns as given below:
Zirtirtu-pa
zirtirtu-nu
Teacher-CL
teacher-CL
Male teacher.
female teacher.
We can also describe the classifiers in terms of the following three features:
- Obligatory:

These noun classification devices are sometimes obligatory sometimes not in Mizo and explicit rules can also be formed for their omission. For example in borrowed words classifiers can be dropped.

-Productivity:

These are very productive in the system and even if a new noun comes into the language classifier is more or less fixed to it.

-Independence:

Like any other classifier language Mizo classifiers can be used as an independent word. 
Example: - pa which is a human masculine classifier is also used as the word for father with a different tone.

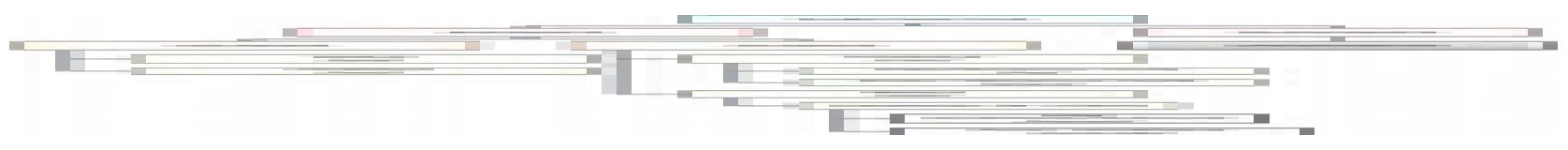

Figure 1Mizo classifier system

Classifier for human male is /pa $\%$ This is a tonal language and that's why tone distinction is very important. Human Female classifier is /nu /. /pá/ and /nú/ are also words for father and mother respectively. For the common distinction between male and female animates, classifiers are /pà/ and /nù/ accordingly. Animate classifiers are also distinctive in case of change of state (reproductive stage and coming out of nail). Horned animals like sheep, goat, and cow take the classifier /pat fəl/ with them. /patfal/ is attached as a classifier to the animals having a nail at the back of leg (cock). Classifiers are different in case of pre-reproduction and post reproduction stages for animates. Before reproduction male animate classifier is /twai/ and female is /la/. After reproduction they are / $\mathrm{t} \int \mathrm{\partial} /$ and /pwi/ respectively. For proper names there are distinction between male and their female counter parts. Classifier /-a/ is adjoined to male names and /-i/ with a female name.

\section{Mizo numeral classifier system}

In Mizo all Human nouns occur with the classifier [mí]. For elongated objects like cigarette, bamboo, wood and battery [tlo:n] is used. Round objects come with [púm]. Flat objects such as paper and plywood take [pe:k] as classifier. For tree and flower classifiers are [ku:y] and [pa:r] respectively. [t $\mathrm{ji}]$ is used to denote the kind of things i.e. the kind of stories, etc.Pieces of objects take the classifier [t ${ }^{\text {hém] }}$. For fruits, egg yolk, eye ball, orange seeds, etc. [mú] is used as the classifier. Food grains are referred by the classifier [fa:n]. [zai] is used to denote small elongated objects like hair, wire, and thread.

\section{Assamese: A neighboring Indo-Aryan Language}


Assamese, which belongs to the Indo-Aryan language family, has a wide range of Noun and Numeral classifiers. However, the number of Numeral classifiers is larger than that of Noun classifiers. Most of the Noun classifier move to a slot near the numeral in the NP and become Numeral classifier. However, there also remain some classifiers which do not raise and become a numeral classifier. The different Noun classifiers can be distinguished on the basis of some semantic concepts such as shape, size, structure, +/-humanness, +/-animacy, +/-honorific, etc.

Some of the classifiers in Assamese are as follows

\begin{tabular}{|c|c|c|}
\hline Classifiers & Type of Noun & Example \\
\hline zupa & plants and trees & $\begin{array}{l}\text { aam-zupa } \\
\text { mango tree-CL } \\
\text { a mango tree }\end{array}$ \\
\hline $\mathbf{k}^{\mathrm{h}} \mathbf{\jmath n}$ & flat structured objects & $\begin{array}{l}\text { bisona-k }{ }^{\mathrm{h}} \text { on } \\
\text { bed-CL } \\
\text { a bed }\end{array}$ \\
\hline dal & branch like/stick like long objects & $\begin{array}{l}\text { suli-dal } \\
\text { hair-CL } \\
\text { hairs }\end{array}$ \\
\hline $\mathbf{k}^{\text {hila }}$ & leaves and pages & $\begin{array}{l}\text { pat-khila } \\
\text { leaf-CL } \\
\text { a leaf }\end{array}$ \\
\hline pah & flowers & $\begin{array}{l}\text { gulap-pah } \\
\text { rose-CL } \\
\text { a rose }\end{array}$ \\
\hline pat & flat structured object that is worn & $\begin{array}{l}\text { kan-phuli-pat } \\
\text { Ear-ring-CL } \\
\text { a ear ring }\end{array}$ \\
\hline thupa $^{\text {h }}$ & bunch of flowers & $\begin{array}{l}\mathrm{p}^{\mathrm{h}} \mathrm{ul}-\mathrm{t}^{\mathrm{h}} \mathrm{upa} \\
\text { flower-CL } \\
\text { flowers }\end{array}$ \\
\hline tupal & liquid drops & $\begin{array}{l}\text { pani-tupal } \\
\text { water-CL } \\
\text { water }\end{array}$ \\
\hline
\end{tabular}

\section{Malto: A neighboring Dravidian Language}

Malto belongs to the Dravidian family of languages. In this language objects are classified along the lines of discreteness and Non discreteness. Animates are classified into +/- Human. Some Classifiers are formed by partial reduplication. It's a very interesting classification system. The general structure of the Noun Phrase is Numeral+ Classifier+ Noun. Animate entities are classified into human and nonhuman.

$$
\text { tini jan } \text { maler }^{1}
$$

1 Mahapatra, B.P. article on 'Malto Numeral classifiers' published in Languages of the tribal and Indigenous people of India. Abbi, Anvita (ed.) 1997 MLBD SERIES IN LINGUISTICS VOL. X. DELHI: Motilal Banarsidass 
Three $\quad$ CL men

Three men

tini maq bu:te ${ }^{2}$

Three CL ghosts

Three ghosts

The reduplicated classifiers are applicable to restricted sets of Nouns such as qep- 'village', man'tree', kir- small plant, kari- hole/cave, kuji- 'shadow/reflection', etc. Interestingly when the numbers are one, two and the noun is -Human the structure of noun phrase changes to Classifier+numeral+Noun.

$\begin{array}{lll}\text { maq-s } & \text { go: } & \text { ro } \\ \text { classfier } & \text { two } & \text { horse } \\ \text { two horses } & & \end{array}$

\section{Malto system of Classification.}

Some of the state classifiers in Malto are: 'baha'- Area, field, market ,place, 'tada'-- small area 'dika'- clod , earth.

When the noun is thuman portmanteau morphs 'ort-' for one and 'irw-' for two occur respectively. Classifier 'jan' is used with human nouns for live referents. 'maq' comes for their non human counterparts. For objects which are long and large the classifier is 'dara'. 'kari' comes with long small objects. Objects that are both long and flexible take 'panda' as a classifier. Use of 'para' is frequent in long fruits. Malto classifier system also distinguishes objects along the line of flatness. Flat, broad objects are used with the classifier 'pata' and 'pata' for flat, broad but thin objects. Kanda is however used with cotton objects that are flat and broad. Round heavy objects occur with 'got' but round, light objects will definitely be produced with the classifier 'pula'. ${ }^{3}$

An interesting construction in the noun phrase can be seen for some nouns e.g. rice, water, etc.

Bu? $\quad \mathrm{p}^{\mathrm{h}} \mathrm{ur}$ ht

Rice CL-action of NUM (one)

carrying rice in a basket

One traditional basket of rice.

publishers.

2 ibid.

$3 \mathrm{~Pa}: \mathrm{n}$ and pand are other two variant forms of this for the number $1 \& 2$ respectively. 
tui kot $\quad \mathrm{k}^{\mathrm{h}}$ ət

Water CL:action of carrying NUM (one)

Water in two buckets with a bamboo pole

Two buckets of water

The same phenomenon occurs with the classifiers in mass nouns [+CUMULATIVE] where mass nouns are classified as a state of action. This is interesting because the action predication seems to be attached with the head noun and serves the purpose of a classifier. However it is not the case that main predication can be dropped even if these phrases are used at sentence level. This is true for mass nouns and indeed can be said a strong case of grammaticalization. Reduplication is an important phenomenon in almost all languages and it is shared across language families. Let's make a comparison between Tibeto Burman languages and that of the Dravidian family.

\begin{tabular}{|c|c|c|c|}
\hline $\begin{array}{l}\text { Name of the } \\
\text { language family }\end{array}$ & Language & Example & Remarks \\
\hline TB & $\begin{array}{l}\text { Mizo } \\
\text { Tagin }\end{array}$ & 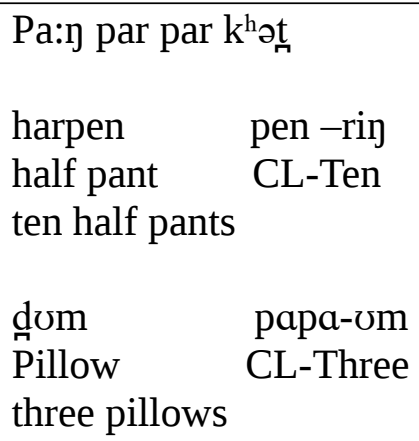 & \begin{tabular}{l}
\multicolumn{1}{c}{ Second } \\
syllable \\
reduplicated
\end{tabular} \\
\hline $\mathrm{DA}$ & Malto & $\begin{array}{ll}\text { qep-ond } & \text { qepdu } \\
\text { CL-NUM } & \text { village } \\
\text { One village } & \end{array}$ & $\begin{array}{l}\text { First syllable } \\
\text { is reduplicated }\end{array}$ \\
\hline
\end{tabular}

\section{Conclusion}

On the basis of the above discussion, it could be seen that there are classifiers in languages belonging to three different families-Tibeto-Burman, Indo-Aryan and Dravidian. While TibetoBurman languages have been widely accepted as classifier languages, Dravidian and Indo-Aryan languages are generally not considered so (even though Eastern Indo-Aryan are being slowly acquiring the status as classifier languages). The presence of this feature in these languages indeed shows that classifiers are an areal feature of these languages. Due to the contact with TB languages for a long time, classifiers may have been borrowed into these languages (very tentatively). However as we could see classifiers in all these languages have very unique features and behave in language-specific ways (except Galo and Tagin, which are very closely related). This is true even for Mizo and the other two TB languages. And because of its uniqueness it cannot be established with conviction whether classifiers have developed by themselves in these languages or they are borrowed. If they are developed by themselves then why have they developed only in these neighbouring languages? And if they are borrowed how come they are so distinct that they bear 
very little resemblance, if any, with each other? It looks like a more nuanced case of linguistic diffusion where a linguistic feature has been borrowed but the exact characteristics of that feature were developed within the language; it was not just borrowed but also worked upon and developed according to their own needs. This aspect needs to be explored more to arrive at some definite conclusion.

\section{References}

Aikhenvald, A Y. Classifiers: a typology of noun categorization devices. Oxford: Oxford University Press(2000).

Aikhenvald, A Y .Classifiers and Noun Classes: Semantics, from 'Encyclopedia of Language and Linguistics' eds Keith Brown (editor-in-chief), Anne Anderson, Laurie Bauer, Margie Burns, Jim Miller and Graeme Hirst (Elsevier Pvt. Ltd., 2006).

Kidwai, Ayesha and Joyshree Sutradhar (2008). The Morpho-Syntax of Classifiers in (three) Indian Languages: The Mass/Count Distinction, presented in CGIML-08 at IIIT-H.

Mahapatra, B.P. (1997). Malto Numeral classifiers, from 'Languages of the tribal and Indigenous people of India' ed Anvita Abbi (Motilal Banarsidass, 1997).

Saha, Atanu. Noun Classification system in Mizo, from 'Language in India' ed M.S. Thirumalai Vol. $8(2008)$. 